\title{
Tejido Tiroideo y Láser Infrarrojo. Un Estudio Morfométrico
}

\author{
Thyroid Tissue and Infrared Laser. A Morphometric Study
}

Ricardo Cornejo ${ }^{1}$; Roberto Jaramillo ${ }^{2}$ Orlando Garrido ${ }^{2} \&$ Luis Vergara ${ }^{1}$

CORNEJO, R.; JARAMILLO, R.; GARRIDO, O. \& VERGARA, L. Tejido tiroideo y láser infrarrojo. Un estudio morfométrico. Int. J. Morphol., 35(3):1091-1094, 2017.

RESUMEN: La glándula tiroides posee gran importancia debido a la síntesis y secreción de hormonas, las cuales desempeñan funciones fundamentales para la mantención de la fisiología animal. En este contexto, el objetivo del presente trabajo consistió en determinar parámetros morfométricos de estructuras tiroideas sometidas a estimulaciones con láser infrarrojo (LIR). Para ello, 10 ratas Sprague Dawley de 3 meses de vida y peso aproximado de $200 \mathrm{~g}$, fueron divididas en dos grupos de 5 animales cada uno: grupo control y grupo experimental. Estos últimos recibieron estimulaciones infrarrojas en la tiroides con dosis de $16 \mathrm{~J} / \mathrm{cm}^{2}$ durante 15 días seguidos. Una vez sacrificadas las ratas, se extrajeron las glándulas tiroides las que fueron procesadas para microscopía óptica obteniéndose placas histológicas y micrografías con aumentos finales de hasta 1000 X. Se efectuaron estudios morfométricos para determinar en 40 placas, variaciones tisulares generadas por las inducciones infrarrojas, con especial énfasis en la disposición coloidal y dimensiones de folículos y células tiroideas. El análisis de las 40 placas histológicas generados por las inducciones del láser infrarrojo comparados con los controles, reveló que existen marcadas diferencias en todos los componentes del tejido tiroideo analizado, lo cual podría otorgar antecedentes de diferentes funcionalidades en el metabolismo de las glándulas.

PALABRAS CLAVE: Tiroides; Morfometría; Láser infrarrojo.

\section{INTRODUCCION}

La glándula tiroides recibe este nombre por su similitud con un escudo (del griego hyreos: escudo), ya que se pensaba que constituía una auténtica protección para la laringe de la misma forma que lo constituye el cartílago tiroides (Cian et al., 2004). Es una glándula endocrina impar, casi simétrica constituída de dos lóbulos unidos por un istmo central, situada justo por debajo de la laringe y a ambos lados y por delante de la tráquea, siendo una de las glándulas endocrinas más grande, con un peso que oscila entre los 15 y 20 gramos en los adultos sanos (Guyton \& Hall, 2011). Su ubicación definitiva la alcanza durante la séptima semana de desarrollo intrauterino (Sadler, 2006).

En lo relativo a la vascularización, la glándula está irrigada por la arteria tiroidea superior (primera rama de la arteria carótida externa), encargada principalmente de la porción superior de la glándula; y por la arteria tiroidea inferior, la cual se origina del tronco tirocervical, que se deriva de la arteria subclavia. Adicionalmente, se ha reportado la presencia de una arteria inconstante, denominada arteria tiroidea ima, la cual tiene una presencia en los diferentes reportes analizados, que varía entre un $10 \%$ y $20 \%$ de la población (Rojas \& Ballesteros, 2009).

Desde el punto de vista funcional, la glándula tiroides comienza a activarse, aproximadamente, al final del tercer mes de desarrollo fetal, cuando se pueden observar los primeros folículos que contienen coloide (Sadler), cuyo componente principal es la tiroglobulina (Tg) (Tresguerres, 1992). El tejido endocrino de esta glándula posee células foliculares (células principales) y parafoliculares (células C). Las primeras, se caracterizan por tener un núcleo esferoidal con uno o más nucléolos prominentes, un Complexus golgiensis (aparato de Golgi) con ubicación supranuclear, desarrollo de retículo endoplásmico rugoso con ubicación basal, así como microvellosidades cortas en su extremo apical y vesículas de reabsorción de coloide. Estas glándulas sintetizan las hormonas tiroxina (T4) y triyodotironina 
(T3), secretadas por estimulación de la TSH que se libera desde el lóbulo anterior de la hipófisis (Ross \& Pawlina, 2007).

La función principal de estas hormonas tiroideas en los adultos es proporcionar sustratos para el metabolismo oxidativo y aumentar el consumo de oxígeno en la mayoría de los tejidos, regulando así el metabolismo y le temperatura corporal. En los niños, son necesarias para la expresión completa de la hormona del crecimiento, lo que significa que son esenciales para el crecimiento y desarrollo normales, sobre todo del sistema nervioso (Silverthorn, 2008).

Las células parafoliculares ubicadas en la periferia del epitelio folicular, se caracterizan por un citoplasma claro, son pálidas y se distribuyen en forma de células solitarias o en cúmulos celulares pequeños. Internamente, presentan muchas vesículas de secreción y un Complexus golgiensis prominente; cuya función es producir y liberar la hormona calcitonina, que se encarga de regular la concentraciones de calcio en la sangre, ya que inhibe la disolución de los cristales de calcio en el hueso y estimula la secreción de calcio por la orina en los riñones. Estas dos acciones dan por resultado la disminución de la calcemia (Fox, 2011). Por lo tanto, la glándula tiroides presenta una estrecha asociación morfológica y funcional con las glándulas paratiroides en la mantención homeostática del organismo.

En base a lo presentado, el tejido tiroideo se constituye en un excelente modelo para cuantificar y por tanto evidenciar las eventuales transformaciones o variaciones de componentes de este tejido generadas por las inducciones del láser infrarrojo (LIR) las que, en otros tipos tisulares, provocan grandes y significativas diferencias en sus células constitutivas resultando, por ende, en una lógica variación de su funcionalidad.

\section{MATERIAL Y METODO}

Para el estudio con microscopía óptica las glándulas tiroides normales y estimuladas durante 15 días consecutivos con LIR $16 \mathrm{~J} / \mathrm{cm}^{2}$, fueron fijadas en formalina al $10 \%$, para proceder a la deshidratación en batería creciente de alcoholes de 50 a $100 \%$ por dos h; posteriormente fueron incluidas en Paraplast durante $12 \mathrm{~h}$. Se realizaron cortes seriados de $7 \mu \mathrm{m}$ de espesor fijándolos a portaobjetos albuminizados y dejando secar por $24 \mathrm{~h}$. El proceso requirió desparafinar con Xilol por 40 min y se realizó la tinción citoplasmática con eosina por 5 min, y la nuclear con hematoxilina por 3 min. Además de tinción con Azul de Toluidina. Luego de un lavado con agua, se deshidrataron los cortes con batería creciente de alcoholes, otorgándoles transparencia mediante xilol fenicado por $5 \mathrm{~min}$. Finalmente se realizó el montaje de los cortes en medio Permount, dejando secar por $24 \mathrm{~h}$, a temperatura ambiente.

Los respectivos cortes de las glándulas tiroides fueron observados y fotografiados en un microscopio Carl Zeiss modelo Axioskop 40, acondicionado con cámara digital incorporada. Para la determinación de áreas y perímetros se utilizó el software Sigma Scan Pro 5.0

\section{RESULTADOS}

El análisis de las evaluaciones realizadas en las placas histológicas con tinción de Azul de Toluidina a las tiroides normales y estimuladas con LIR mediante métodos morfométricos permitió consignar los resultados que se presentan en las Figuras 1 y 2, y en las Tablas I y II.

Tabla I. Evaluaciones del tejido tiroideo de ratas normales.

\begin{tabular}{|c|c|c|c|}
\hline & Diámetro celular $\mu \mathrm{m}$ & Área del coloide $\mu \mathrm{m}^{2}$ & Área del folículo $\mu \mathrm{m}^{2}$ \\
\hline Promedio & 3,669 & 252,336 & 326,471 \\
\hline Desviación están dar & 0,718 & 98,047 & 108,343 \\
\hline Error estándar & 0,065 & 32,682 & 36,114 \\
\hline
\end{tabular}

Tabla II. Evaluaciones del tejido tiroideo de ratas estimuladas con dosis infrarrojas de $16 \mathrm{~J} / \mathrm{cm}^{2}$.

\begin{tabular}{|c|c|c|c|}
\hline & Diámetro celular $\mu \mathrm{m}$ & Área del coloide $\mu \mathrm{m} 2$ & Área del folículo $\mu \mathrm{m}^{2}$ \\
\hline Promedio & 5,921 & 180,857 & 242,452 \\
\hline Desviación estándar & 1,493 & 79,319 & 93,997 \\
\hline Error estándar & 0,121 & 26,44 & 29,724 \\
\hline
\end{tabular}




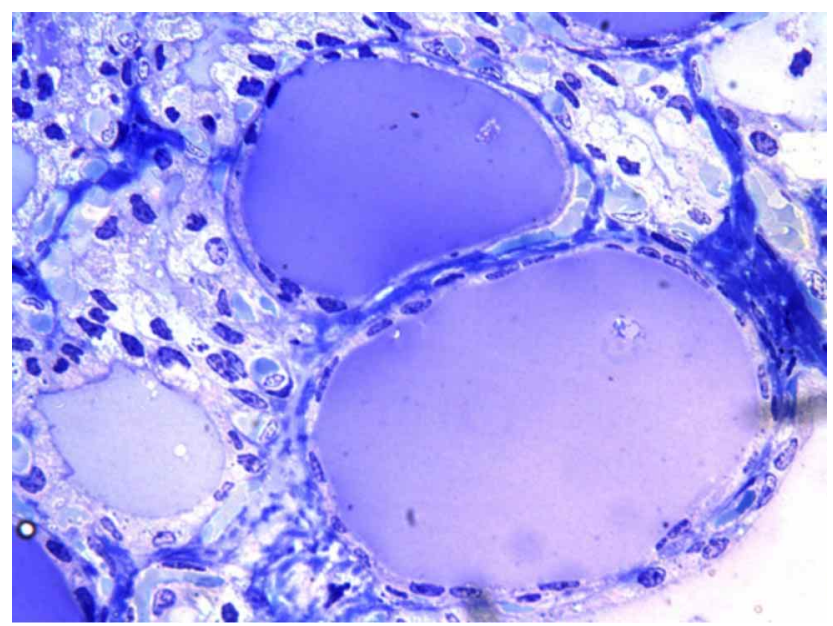

Fig. 1. Micrografía óptica correspondiente a tejido tiroideo de rata normal, evidenciando constituyentes tisulares y enfatizando folículos, disposición coloidal y células foliculares. Tinción Azul de Toluidina. $1000 \mathrm{X}$.

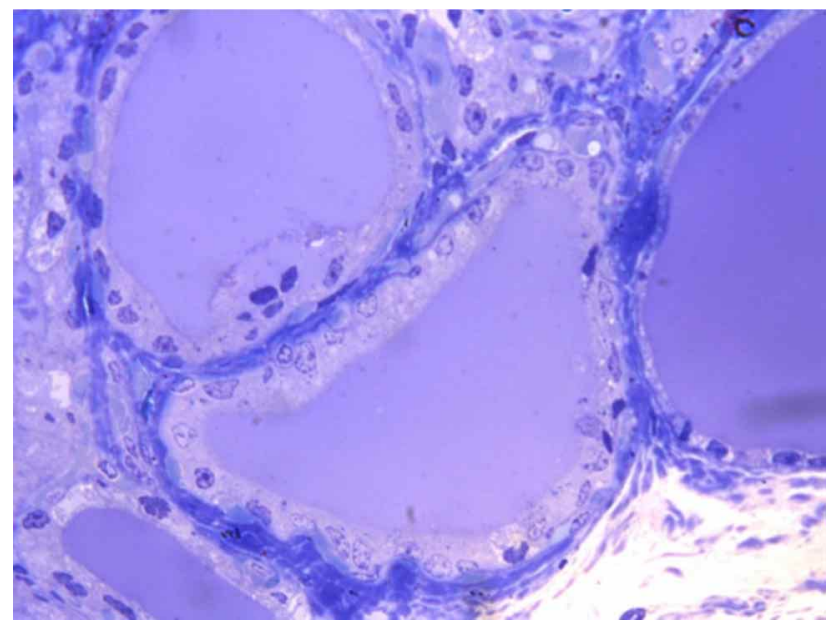

Fig. 2. Micrografía óptica de tejido tiroideo de rata estimulado con LIR y dosis de $16 \mathrm{~J} / \mathrm{cm}^{2}$, evidenciando constituyentes tisulares y enfatizando folículos, disposición coloidal y células foliculares Tinción Azul de Toluidina. 1000 X.

\section{DISCUSION}

Las estimulaciones con LIR y dosis de $16 \mathrm{~J} / \mathrm{cm}^{2}$ indican, en base al análisis de nuestros resultados y con absoluta claridad, su capacidad de generar drásticas modificaciones tanto a nivel celular como en los constituyentes fundamentales del tejido tiroideo.

En este contexto, en lo referente a los resultados obtenidos y mostrando una evaluación correspondiente al diámetro de las células foliculares derivadas de tiroides normal en relación con su contrapartida estimulada con LIR, se visualiza una importante diferencia equivalente a $2.25 \mathrm{u}$, sin duda como respuesta a las inducciones infrarrojas. Este hecho guarda directa relación con lo descrito por Das \& Kalyani (2008), quienes con microscopía óptica observaron tejido tiroideo alterado, con folículos de morfología y tamaño variables mezclados entre sí, contornos rígidos y plegamientos internos, que representan señales de hiperfunción y donde sus células foliculares poseen un volumen muy superior, en comparación a células foliculares normales.

De igual manera, esta importante diferencia de volumen, aproximadamente al doble, cuantificada entre células foliculares normales e irradiadas de ratas Wistar machos, ha sido descrita por Rognoni et al. (1989).

Por otra parte, a partir de las evaluaciones descritas en nuestros resultados, relativas tanto a las áreas correspondiente al coloide como del propio folículo tiroideo, encontramos una relación directa entre estos valores puesto que, en ambos aspectos, las inducciones infrarrojas generan una drástica disminución en los parámetros citados, dejando claro que las estimulaciones podrían activar la síntesis de hormonas tiroideas, dado al aumento de volumen traducido en hipersecreción y aumento celular que determinaría una notable disminución de las áreas tanto folicular como coloidal. Este resultado, y sus respectivas variaciones morfológicas y morfométricas, queda claramente descrito en la "enfermedad de Graves" o simplemente "hipertiroidismo", situación donde el grado de estimulación de la glándula produce un aumento considerable en la altura de las células foliculares, transformándolas de cúbicas a cilíndricas, aumentando la síntesis y la utilización del coloide y por ende disminuyendo su cantidad (Ross et al., 2006). Todo esto se traduce en irregularidad folicular, incluso apariencia vacía en las regiones de contacto con la superficie apical de las células foliculares (Ross et al.).

En un claro antagonismo con este resultado, Azevedo et al. (2005), trabajando en ratas Swiss albinas, estimularon tejido tiroideo con láser infrarrojo y dosis de $4 \mathrm{~J} / \mathrm{cm}^{2}$ y a través de microscopía óptica indicaron que no se producía ninguna modificación morfológica en el epitelio folicular, probando entonces que las modificaciones celulares o tisulares, producto de las estimulaciones, son extremadamente dependientes de las dosis utilizadas. Asimismo, Parrado et al. (1990) probaron que existe una directa relación entre las eventuales modificaciones morfológicas y la energía de la radiación utilizada.

Los resultados indicarían que en la medida que se estimule con una determinada dosis de LIR el tejido tiroideo, se generan incrementos e inhibiciones tanto de las células como de las estructuras tisulares, lo que podría traducirse en distintas funcionalidades de esta glándula. 
CORNEJO, R.; JARAMILLO, R.; GARRIDO, O. \& VERGARA, L. Thyroid tissue and infrared laser. A morphometric study. Int. J. Morphol., 35(3):1091-1094, 2017.

SUMMARY: The thyroid gland is of great importance because of the synthesis and secretion of hormones which play key roles in the maintenance of animal physiology. In this context, the aim of the present study was to determine morphometric parameters of thyroid structures subjected to infrared laser stimulation (ILS) and for this purpose, 10 Sprague Dawley rats, 3 months of age and weighing approximately 200 grams, were divided into two groups of 5 animals each: the control group and the remaining 5 animals constituting the experimental group received infrared stimulation in the thyroid with doses of $16 \mathrm{~J} / \mathrm{cm} 2$ for 15 consecutive days. After the rats were sacrificed, the respective thyroids were removed and processed for optical microscopy. Histological plates and micrographs were obtained with final increases of up to $1000 \mathrm{X}$. Morphometric studies were carried out to determine the tissue variations generated by infrared inductions, with special emphasis on the colloidal arrangement and dimensions of follicles and thyroid cells. Our results revealed that there are marked differences in all the components of the analyzed thyroid tissue which could give antecedents of different functionalities in the metabolism of thyroid glands.

KEY WORDS: Thyroid; Morphometry; Infrared laser.

\section{REFERENCIAS BIBLIOGRAFICAS}

Azevedo, L. H.; Aranha, A. C.; Stolf, S. F.; Eduardo, C. de P. \& Vieira, M. M. Evaluation of low intensity laser effects on the thyroid gland of male mice. Photomed. Laser Surg., 23(6):567-70, 2005.

Cian, D. M.; Demarchi, R. V.; Gay, C. N. \& Pérez, M. M. Patología tiroidea. Prevalencia de patología benigna y maligna. Rev. Posgrado VIa Cátedra Med., (135):17-20, 2004.

Das, S. \& Kalyani, R. Sclerosing mucoepidermoid carcinoma with eosinophilia of the thyroid. Indian J. Pathol. Micr obiol., 51(1):34-6, 2008.

Fox, S. I. Fisiología Humana. 12a ed. Ciudad de México, MacGraw-Hill Interamericana, 2011. pp.337-40.

Guyton, A. C. \& Hall, J. E. Guyton \& Hall. Tratado de Fisiología Médica. $12^{\mathrm{a}}$ ed. Barcelona, Elsevier, 2011. pp.907-14.

Parrado, C.; Peláez, A.; Vidal, L. \& Pérez De Vargas, I. Quantitative study of the morphological changes in the thyroid gland following IR laser radiation. Lasers Med. Sci., 5(1):77-80, 1990.

Rognoni, J. B.; Penel, C.; Bastiani, P.; Roccabianca, M. \& LemarchandBeraud, T. Down regulation of hypertrophied follicular cell volume in thyroid hyperplastic gland. Histol. Histopathol., 4(2):193-200, 1989.

Rojas, O. J. D. \& Ballesteros, A. L. E. Branches arise of the aortic arch in human fetus. a descriptive direct study in colombian population. Int. J. Morphol., 27(4):989-96, 2009.

Ross, M. H.; Kaye, G. I. \& Pawlina, W. Histología. Texto y Atlas Color con Biología Celular y Molecular. Buenos Aires, Médica Panamericana, 2006. pp.657-60.

Ross, M. H. \& Pawlina, W. Histología. Texto y Atlas Color con Biología Celular y Molecular. $5^{\circ}$ edición. Buenos Aires, Médica Panamericana, 2007. pp.753-8.

Sadler, T. W. Langman. Embriología Médica con Orientación Clínica, $9^{\mathrm{a}}$ ed. Buenos Aires, Médica Panamericana, 2006. pp.353-5.

Silverthorn, D. U. Fisiología Humana. Un Enfoque Integrado. $4^{\mathrm{a}}$ ed. Buenos Aires, Médica Panamericana, 2008. pp.85-100.

Tresguerres, J. A. F. Fisiología Humana. $3^{\mathrm{a}}$ ed. Madrid, MacGraw-Hill Interamericana, 1992. pp.891-8.

Dirección para correspondencia:

Dr. Ricardo Cornejo U.

Depto. Ciencias Básicas

Facultad de Medicina

Universidad de La Frontera

Temuco - CHILE

Email: rene.cornejo@ufrontera.cl

Recibido: 04-09-2016

Aceptado:28-07-2017 